\title{
A Prospective Analysis of Sexual Behaviors of Pregnant Women in Southeast Turkey
}

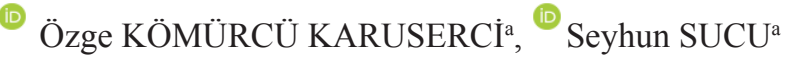 \\ aDepartment of Gynecology and Obstetrics, Gaziantep University Faculty of Medicine, Gaziantep, TURKEY
}

\begin{abstract}
Objective: The aim of this cross-sectional survey study was to prospectively evaluate the changes in sexual behaviours of pregnant women in Southeast Turkey which is under different pressures, either culturally or religiously according to the other regions of Turkey. Material and Methods: Three hundred pregnant women completed a 25-question survey about their sexual life. The questions were prepared based on the Female Sexual Function Index (FSFI) and the Body Exposure during Sexual Activities Questionnaire (BESAQ) tests. Results: Sexual desire decreased in $65.2 \%$ of women $(n=163)$ and increased in $8.4 \%(n=21)$. The rate of orgasms was $55.6 \%(n=139)$, and higher during anal intercourse $(\mathrm{p}=0.038)$. The orgasm rate before and during pregnancy was similar $(\mathrm{p}=0.72)$. The orgasm/satisfaction was higher during anal intercourse compared to that during vaginal intercourse $(p=0.038)$. Sixty five percent of the women were worried about coitus during pregnancy $(n=176)$. However, $85.7 \%$ of the pregnant women $(n=257)$ had regular sexual intercourse to maintain a healthy partnership $(40 \%)$ or for desire $(23 \%)$. There was no significant relationship between intercourse frequency and education level ( $\mathrm{p}=0.81)$, abortion history $(\mathrm{p}=0.63)$, age $(\mathrm{p}=0.21)$, and gestational week $(\mathrm{p}=0.81)$. Sexual desire remained mostly unchanged in women following their first, second, and third births $(61.1 \%, 61.7 \%$, and $69.8 \%$, respectively). Conclusion: Our results suggest that despite the geographical, cultural and social differences between the southeast region and other regions, the fact that sexual life during pregnancy has similar characteristics for every women shows that sexual physiology is independent from external factors.
\end{abstract}

Keywords: Pregnancy; sexual behaviour; Turkey; culture

Pregnancy is a very special period of time in which a woman experiences many hormonal, physical, and psychological changes. Along with these changes, social, biological, economic, ethical, cultural, and religious features affect sexual behavior during pregnancy. Previous studies reported that pregnancy has a negative effect on sexual desire, satisfaction, and coital frequency, especially during the first and third trimesters..$^{1-3}$ Certain beliefs that are often wrong and physical discomfort associated with pregnancy are some of the reasons for the decrease in coital frequency. ${ }^{4,5}$ Common reasons for physical discomfort are a growing abdomen, weight gain, and nausea, especially during the first trimester. Variable emotions and anatomical changes in the women sometimes force couples to attempt alternative sexual positions. These factors may contribute to a decrease in sexual desire. Incorrect myths about harming the fetus (causing a miscarriage or infection) or inducing labor may also decrease coital frequency and sexual desire. Furthermore, religious prohibitions, thoughts of being a parent, lack of interest of partner, and a change in the woman's sexual identity also affects sexual life during pregnancy. In contrast, there are also positive beliefs that sex during pregnancy facilitates birth and contributes to the well-being of the baby. ${ }^{6}$

There are a number of previous studies regarding the sexual life of women from different regions of Turkey during and after pregnancy. ${ }^{7-9}$ However, there have been no reports studying women from the Southeast Anatolia Region of Turkey. This area has a very similar culture with Arab countries because of its shared border and has more conservative behaviors compared to the other regions of Turkey. ${ }^{10}$

Correspondence: Özge KÖMÜRCÜ KARUSERCI

Department of Gynecology and Obstetrics, Gaziantep University Faculty of Medicine, Gaziantep, TURKEY E-mail: ozgekomurcu@hotmail.com

Peer review under responsibility of Journal of Clinical Obstetrics \& Gynecology. 


\section{OBJECTIVES}

The main objective of this study was to evaluate the changes in sexual behaviors, sexual desires, and satisfaction of women living in Southeast Turkey during and after pregnancy compared with the pre-pregnancy period. As far as we know this is the first study that researches about the sexuality during pregnancy in Southeast Turkey.

\section{MATERIAL AND METHODS}

This cross-sectional and descriptive study was conducted in the obstetrics clinic between January 2018 and July 2019. The non-drug clinical research ethical approval for this prospective study was obtained from the Clinical Research Ethics Committee (Approval date: June 2017, number: 2017/225). Informed consents were obtained from all participants. All reported research involving 'human beings' conducted in accordance with the principles set forth in the Helsinki Decleration 2008. ${ }^{11}$

Healthy, heterosexual pregnant women $(n=300)$ who had been living with their partners were randomly included in this study. Women with pregnancy complications in any trimester, such as premature rupture of the membrane, placenta previa, and antepartum bleeding, and those who were advised to avoid coitus by a physician due to a medical condition were excluded. All participants included in our study were informed that they would be required to answer questions about their sexual life during pregnancy in one to one conversation. Some of the participants filled out the questionnaire themselves and some of them answered the questions posed by the clinician.

The questionnaire included 25 questions regarding sexual activity, desire, orgasm, and preferred position. Factors affecting sexual behavior and concerns about coitus during pregnancy were also determined. The questions were prepared based on the Female Sexual Function Index (FSFI) and the Body Exposure during Sexual Activities Questionnaire (BESAQ) tests. ${ }^{12,13}$

This self-report questionnaire had two sections. The first section was designed to collect demographic information including age, occupation, gravity and parity, and education level. In addition, smoking or alcohol use during pregnancy was also questioned. The second section of the questionnaire was designed to collect the sexual perceptions and activities during pregnancy. The questions were as follows: sexual desire in pregnancy (increased, decreased, unchanged), regular intercourse during pregnancy (yes or no), sexual satisfaction/orgasm (yes or no), satisfaction/orgasm (vaginal, anal, oral), worry about sexual intercourse (yes or no), preferred sexual intercourse (vaginal, anal, oral), and sexual desire after the first, second, and third births (increased, decreased, unchanged).

The normality of distribution of continuous variables was tested by Shapiro-Wilk test. Student's t test was used for the comparison of two independent groups of variables with a normal distribution and Mann-Whitney U test was used for the comparison of two independent groups of variables with a nonnormal distribution. Analysis of variance (ANOVA) and least significant difference (LSD) tests were used for three independent groups of variables with normal distribution and Kruskal Wallis, and all subset multiple comparison tests were used for comparison of more than three independent groups of variables with a non-normal distribution. Chi-square test was used to assess the relationship between categorical variables. Descriptive statistic parameters are presented as frequency, percentage (\%), and mean \pm standard deviation (mean $\pm \mathrm{SD}$ ). Statistical analysis was performed with SPSS for Windows version 22.0 and $p$ value $<0.05$ was accepted as statistically significant.

\section{RESULTS}

The demographic characteristics of all participants are presented in Table 1 .

Some women did not want to answer certain questions. Therefore, the results are evaluated from only the respondents. Sexual desire decreased in most of the pregnant women $(65.2 \%)$ and increased in only a small part (8.4\%), while the remaining portion reported no difference between non-pregnant state and pregnancy. On the other hand, sexual desire remained 
TABLE 1: Demographic characteristics of the study population.

\begin{tabular}{|lcccc|}
\hline & & & & Standard \\
Age (years) & 18.00 & 46.00 & 28.5233 & 5.95547 \\
Gravity & 1.00 & 6.00 & 2.1185 & 1.09987 \\
Parity & 1.00 & 5.00 & 1.6290 & .91481 \\
\hline Number of living children & 1.00 & 5.00 & 1.9378 & .99805 \\
\hline
\end{tabular}

mostly unchanged in women following their first, second, and third births $(61.1 \%, 61.7 \%$, and $69.8 \%$, respectively) (Figure 1).

Sixty five percent of the women were worried about coitus during pregnancy. However, $85.7 \%$ of the pregnant women had regular sexual intercourse in order to maintain a healthy partnership $(40 \%)$ or for desire $(23 \%)$. The major concerns about sexual intercourse were an early birth (43\%) and religious prohibitions (48\%). The other reasons for decline in sexual desire during pregnancy were discomfort (27\%), physical and physiological changes (32\%), and reluctance of their partner (13\%). Seventy one percent of the pregnant women preferred vaginal intercourse, for the women to be on top (68\%), and $25 \%$ preferred the anal position. The orgasm/satisfaction rate was $55.6 \%$ and was higher during anal intercourse compared to that during vaginal intercourse $(\mathrm{p}=0.038)$. The orgasm rate before and during pregnancy was similar $(57.2 \%$ and $55.6 \%$, respectively) $(\mathrm{p}=0.72)$. There was no significant relationship between intercourse frequency and education level $(p=0.81)$, abortion history $(p=0.63)$, age

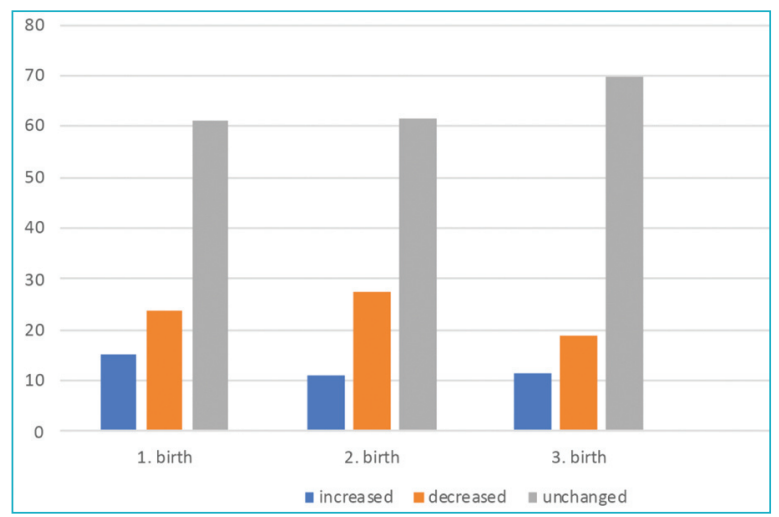

FIGURE 1: Changes in sexual desire of pregnant women after birth. $(p=0.21)$, and gestational week $(p=0.81)$. Sexual intercourse concerns during pregnancy were significantly higher in women with a higher education (university or master's level) ( $\mathrm{p}=0.03)$. There was no significant relationship between orgasm rate and previous number of births ( $p=0.71$ ), mode of delivery (caesarean section/operative vaginal delivery/normal delivery) $(\mathrm{p}=0.90)$, age $(\mathrm{p}=0.32)$, smoking $(\mathrm{p}=0.30)$, and gestational week $(\mathrm{p}=0.64)$. Discomfort level raised as the gestational weeks increased $(\mathrm{p}=0.003)$. The general characteristics and sexuality information of all participants are in Table 2.

\section{DISCUSSION}

Pregnancy is an important and exciting time in a woman's life, however, it may change sexual functions and cause a decline in sexuality. ${ }^{14}$ These changes should be managed well because sexual intercourse is a significant component in a relationship for many couples and an indispensable part of a healthy pregnancy. ${ }^{15}$

The main contributing factors causing a decline in sexuality during pregnancy are hormonal and physical changes resulting in a feeling of lack of attractiveness, and loss of interest in sexuality. ${ }^{16}$ This decline is especially seen in the first trimester of pregnancy and depends on the level of fatigue, fear of causing a miscarriage, pain, breast tenderness, and nausea. ${ }^{17,18}$

In the current literature, a few studies have stated that there is no change in sexual desire during pregnancy, or it may even improve during pregnancy. ${ }^{19,20}$ However, most of the reported studies have demonstrated a decline in sexual desire throughout pregnancy compared to the pre-pregnancy period. ${ }^{21,22}$ In our study, we also found a decline in sexual desire during pregnancy. The major reasons we saw for the decline were the concerns about premature rupture of the membranes and early birth, discomfort, reluctance of the partner, and religious prohibitions. These reasons, except for religious prohibitions, were also reported in previous studies. ${ }^{23}$ On the other hand, we found that sexual desire after birth is similar to the pre-pregnancy period. Therefore, the decline in sexual desire is specific to pregnancy and is restored to a woman's normal level after birth. 


\begin{tabular}{|c|c|c|c|}
\hline Variables & Options & Count $(n)^{*}$ & $\begin{array}{c}\text { Percentage } \\
(\%)\end{array}$ \\
\hline \multirow[t]{5}{*}{ Education level ( $n=299)$} & Literate & 26 & 8.7 \\
\hline & Primary school & 97 & 32.4 \\
\hline & Secondary school & 70 & 23.4 \\
\hline & High school & 70 & 23.4 \\
\hline & University or master & 36 & 12 \\
\hline \multirow[t]{5}{*}{ Occupation (n=299) } & Housewife & 265 & 88.6 \\
\hline & Self-employed & 15 & 5.0 \\
\hline & Civil servant & 14 & 4.7 \\
\hline & Academician & 4 & 1.3 \\
\hline & Worker & 1 & 0.3 \\
\hline \multirow[t]{2}{*}{ Smoking $(n=296)$} & Yes & 38 & 12.8 \\
\hline & No & 258 & 87.2 \\
\hline \multirow[t]{4}{*}{ Duration of smoking } & 1 month & 12 & 31.6 \\
\hline & 3 months & 10 & 26.3 \\
\hline & 6 months & 3 & 7.9 \\
\hline & During the entire pregnancy & 13 & 34.2 \\
\hline \multirow[t]{2}{*}{ Drinking $(n=293)$} & Yes & 4 & 1.4 \\
\hline & No & 289 & 98.6 \\
\hline \multirow[t]{4}{*}{ Frequency of drinking } & Once a week & 2 & 50 \\
\hline & Twice a week & 1 & 25 \\
\hline & Three times a week & 0 & 0 \\
\hline & Once a month & 1 & 25 \\
\hline \multirow{3}{*}{$\begin{array}{l}\text { Sexual desire during } \\
\text { pregnancy }(n=250)\end{array}$} & Increased & 21 & 8.4 \\
\hline & Decreased & 163 & 65.2 \\
\hline & Unchanged & 66 & 26.4 \\
\hline \multirow{2}{*}{$\begin{array}{l}\text { Regular intercourse } \\
\qquad(\mathrm{n}=300)\end{array}$} & Yes & 257 & 85.7 \\
\hline & No & 43 & 14.3 \\
\hline Satisfaction/orgasm & Yes & 139 & 55.6 \\
\hline$(n=250)$ & No & 111 & 44.4 \\
\hline \multirow{2}{*}{$\begin{array}{l}\text { Worried about sexual } \\
\text { intercourse }(n=271)\end{array}$} & Yes & 176 & 65 \\
\hline & No & 95 & 35 \\
\hline \multirow{3}{*}{$\begin{array}{l}\text { Preferred sexual } \\
\text { intercourse }(n=280)\end{array}$} & Vaginal & 198 & 71 \\
\hline & Anal & 70 & 25 \\
\hline & Oral & 12 & 4 \\
\hline
\end{tabular}

${ }^{*}$ Totals vary depending on the number of participants who responded to each question. The number of patients answering the questions is indicated in brackets

Furthermore, it is normal to expect changes in the preferred sexual position or type of sexual intercourse due to physiological conditions of women during pregnancy. In the present study, most participants preferred vaginal intercourse compared with anal and oral intercourse. Most of the previously reported studies support our findings and state that approximately three quarters of pregnant women had vaginal intercourse, while some had anal intercourse because they thought vaginal intercourse may harm the fetus..$^{24,25}$
Erenel et al. declared that most pregnant women were not satisfied with their sexual intercourse; however, Corbacioglu et al. found that a woman's sexual satisfaction remained stable during pregnancy and the postpartum period. ${ }^{718} \mathrm{We}$ also found that most of the pregnant women in our study were generally satisfied at the end of sexual intercourse and there was no difference between pre-pregnancy and pregnancy periods. Besides, our results showed that the rate of orgasm was higher during anal intercourse compared to other styles.

Interestingly, concern regarding sexual intercourse during pregnancy was significantly higher in women with a higher level of education (university and master levels). On the other hand, we could not find a relationship between the frequency of sexual intercourse with descriptive variables such as age, gravity, parity, number of births, living children, educational level, occupation, or medication/smoking/drinking status. Another study from Turkey also reported no statistically significant differences between coitus frequency and these general characteristics. ${ }^{15}$

The findings of previous studies on the sexual behaviors of pregnant women living in Turkey's other regions is similar to our study. ${ }^{2,7-9,15-18,20}$ People living in the Southeast Turkey are under more traditional and religious pressure compared to the other regions due to the proximity of the Arab countries. ${ }^{26}$ Also particularly low education level of women, the implementation of more rigid İslamic rules and strict moral rules make this region different than the other regions. ${ }^{27}$ Despite the obvious cultural differences between the southeast region and other regions, our study's results show that regional differences do not have a significant effect on the sexual life habits during pregnancy in Turkey.

Our study has some limitations. First, there may be a contradiction in the answers because women were not with their husbands. Second, Turkish women living in Southeast Turkey may hesitate to talk about their sexual life due to religious and moral rules, causing them to give inaccurate answers to the questions.

\section{CONCLUSION}

Sexual desire decreases prominently and sexual behaviors change during pregnancy in women of South- 
east Turkey. The loss of sexual desire is caused by psychological and physical changes during pregnancy, religious prohibitions, and also concerns about possible negative effects on pregnancy outcomes. Nevertheless, most pregnant women maintain a regular sexual life to keep their partner around. Therefore, pregnant women should ask for counselling from an expert to minimize the emotional stresses caused by sexuality concerns. Patients should also be informed that regular sexual intercourse during pregnancy does not have negative effects on pregnancy outcomes. Consequently, the most striking result of our study is that regional differences in Turkey have no effect on the sexual behaviours during pregnancy.

\section{Source of Finance}

During this study, no financial or spiritual support was received neither from any pharmaceutical company that has a direct con- nection with the research subject, nor from a company that provides or produces medical instruments and materials which may negatively affect the evaluation process of this study.

\section{Conflict of Interest}

No conflicts of interest between the authors and / or family members of the scientific and medical committee members or members of the potential conflicts of interest, counseling, expertise, working conditions, share holding and similar situations in any firm.

\section{Authorship Contributions}

Idea/Concept: Özge Kömürcü Karuserci, Seyhun Sucu; Design: Özge Kömürcü Karuserci; Control/Supervision: Seyhun Sucu; Data Collection and/or Processing: Özge Kömürcü Karuserci; Analysis and/or Interpretation: Özge Kömürcü Karuserci; Literature Review: Seyhun Sucu; Writing the Article: Özge Kömürcü Karuserci; Critical Review: Özge Kömürcü Karuserci; References and Fundings: Özge Kömürcü Karuserci; Materials: Özge Kömürcü Karuserci.

\section{REFERENCES}

1. Babazadeh R, Najmabadi KM, Masomi Z. Changes in sexual desire and activity during pregnancy among women in Shahroud, Iran. Int J Gyanecol Obstet. 2013;120(1):82-4.[Crossref] [PubMed]

2. Küçükdurmaz F, Efe E, Malkoç Ö, Kolus E, Amasyalı AS, Resim S. Prevalence and correlates of female sexual dysfunction among Turkish pregnant women. Turk J Urol. 2016;42(3):178-83.[Crossref] [PubMed] [PMC]

3. Ribeiro MC, de Tubino Scanavino M, do Amaral MLS, de Moraes Horta AL, Torloni MR. Beliefs about sexual activity during pregnancy: a systematic review of the literature. J Sex Marital Ther. 2017;43(8):82232.[Crossref] [PubMed]

4. Arousell J, Carlbom A. Culture and religious beliefs in relation to reproductive health. Best Pract Res Clin. Obstet Gynaecol. 2016;32:77-87.[Crossref] [PubMed]

5. Jamali S, Mosalanejad L. Sexual dysfunction in Iranian pregnant women. Iran J Reprod Med. 2013;11(6):479-86. [PubMed]

6. Staruch M, Kucharczyk A, Zawadzka K, Wielgos M, Szymusik I. Sexual activity during pregnancy. Neuroendocrinol Lett. 2016;37(1): 53-8. [PubMed]

7. Corbacioglu A, Bakir VL, Akbayir O, Cilesiz Goksedef $\mathrm{BP}, \mathrm{Akca} A$. The role of pregnancy awareness on female sexual function in early gestation. J Sex Med. 2012;9(7):1897-903.[Crossref] [PubMed]

8. Kisa S, Zeyneloğlu S, Yilmaz D, Güner T. Quality of sexual life and its effect on marital adjustment of Turkish women in pregnancy. J Sex Marital Ther. 2014;40(4):309-22.[Crossref] [PubMed]

9. Yanikkerem E, Goker A, Ustgorul S, Karakus A. Evaluation of sexual functions and marital adjustment of pregnant women in Turkey. Int $\mathrm{J}$ Impot Res. 2016;28(5):176-83.[Crossref] [PubMed]
10. Costa E. Social media in Southeast Turkey: Love, kinship and politics. UCL Press; 2016. [Link]

11. Puri KS, Suresh KR, Gogtay NJ, Thatte UM Declaration of Helsinki, 2008: implications for stakeholders in research. J Postgrad Med. 2009; 55(2):131-4.[Crossref] [PubMed]

12. Rosen R, Brown C, Heiman J, Leiblum S, Meston C Shabsigh $\mathrm{R}$, et al. The Female Sexual Function Index (FSFI): A multidimensional self-report instrument for the assessment of female sexual function. J Sex Marital Ther. 2000;26(2):191-208.[Crossref] [PubMed]

13. Cash TF, Maikkula CL, Yamamiya Y. Baring the body in the bedroom: Body image, sexual self-schemas, and sexual functioning among college women and men. Electron J Hum Sex. 2004;7:1-9. [Link]

14. Ninivaggio C, Rogers RG, Leeman L, Migliaccio L, Teaf D, Qualls C. Sexual function changes during pregnancy. Int Urogynecol J. 2017;28(6):923-9. [Crossref] [PubMed]

15. Akyuz MD, Turfan EC, Oner SC, Sakar T, Aktay DM Sexual functions in pregnancy: different situations in near geography: a case study on Turkey, Iran and Greece. J Matern-Fetal Neo M. 2020;33(2):222 9.[Crossref] [PubMed]

16. Erbil N. Sexual function of pregnant women in the third trimester. Alexandria Med J. 2018;54(2):13942.[Crossref]

17. Aslan G, Aslan D, Kizilyar A, Ispahi C, Esen A. A prospective analysis of sexual functions during pregnancy. Int J Import Res. 2005;17(2):154-7.[Crossref] [PubMed]

18. Erenel AS, Eroglu K, Vural G, Dilbaz B. A pilot study: in what ways do women in Turkey experience a change in their sexuality during pregnancy? Sex Disabil. 2011;29(3):207-16.[Crossref]
19. Vannier SA, Rosen NO. Sexual distress and sexual problems during pregnancy: associations with sexual and relationship satisfaction. J Sex Med. 2017;14(3):387-95. [Crossref] [PubMed]

20. Yıldız H. The relation between prepregnancy sexuality and sexual function during pregnancy and the postpartum period: a prospective study. J Sex Marital Ther. 2015;41(1): 49-59. [Crossref] [PubMed]

21. Senkumwong N, Chaovisitsaree S, Rugpao S, Chandrawongse W, Yanunto $\mathrm{S}$. The changes of sexuality in Thai women during pregnancy. J Med Assoc Thai. 2006;89(suppl 4):124-9. [PubMed]

22. Jawed Wessel S, Santo J, Irwin J. Sexual activity and attitudes as predictors of sexual satisfaction during pregnancy: A multi-level model describing the sexuality of couples in the first 12 weeks. Arch Sex Behav. 2019:48(3):843-54.[Crossref] [PubMed]

23. Jawed-Wessel S, Sevick E. The impact of pregnancy and childbirth on sexual behaviors: a systematic review. J Sex Res. 2017;54(4-5):411-23. [Crossref] [PubMed]

24. Sassine D, Ghulmiyyah L, Atallah S, Ghieh D, Saleh N, Slim S, et al. Sexual Changes During Pregnancy in a Middle-Eastern Population. Sex Cult. 2020;24(3):1232-51.[Crossref]

25. Livingstone JD, Ralte L, Magar JT, Chaudhuri S, Cherian AG, Mohan VR. Sexual behaviour in pregnancy among antenatal women attending a secondary hospital in southern India. Int J Community Med Public Health. 2018;5(8):3501.[Crossref]

26. Gündüz Hosgör Ayse, JPJM Smits. The status of rural women in Turkey: What is the role of regional differences. NiCE. 2006.[Link]

27. Harris Leila M. Modernizing the nation: Postcolonialism, postdevelopmentalism, and ambivalent spaces of difference in southeastern Turkey. Geoforum. 2008;39(5):1698-708. [Crossref] 